Jurnal Matematika UNAND

Vol. 1 No. 2 Hal. $21-27$

ISSN : 2303-291X

(C)Jurusan Matematika FMIPA UNAND

\title{
DIMENSI PARTISI GRAF GIR
}

\author{
REFINA RIZA \\ Program Studi Matematika, \\ Fakultas Matematika dan Ilmu Pengetahuan Alam, Universitas Andalas Padang, \\ Kampus UNAND Limau Manis Padang, Indonesia \\ refina.riza@gmail.com
}

\begin{abstract}
Abstrak. Misalkan $G=(V, E)$ adalah graf terhubung dan $S \subseteq V(G)$. Selanjutnya misalkan terdapat titik $v \in V(G)$. Maka jarak titik $v$ terhadap $S$ didefinisikan sebagai $d(v, S)=\min \{d(v, x) \mid x \in S\}$. Misalkan himpunan titik $V(G)$ dipartisi menjadi beberapa partisi, sebut $S_{1}, S_{2}, \cdots, S_{k}$. Notasikan $\pi$ sebagai suatu himpunan terurut dari k-partisi, tulis $\pi=\left\{S_{1}, S_{2}, \cdots, S_{k}\right\}$. Misalkan terdapat suatu titik $v$ di $G$. Maka representasi $v$ terhadap $\pi$ didefinisikan sebagai $r(v \mid \pi)=\left(d\left(v, S_{1}\right), d\left(v, S_{2}\right), \cdots, d\left(v, S_{k}\right)\right)$. Jika setiap titik yang berbeda di $G$ mempunyai representasi yang berbeda terhadap $\pi$, maka $\pi$ disebut sebagai partisi penyelesaian. Kardinalitas minimum dari k-partisi penyelesaian terhadap $V(G)$ disebut dengan dimensi partisi dari $G$, dinotasikan dengan $p d(G)$.

Misalkan terdapat graf siklus genap $C_{2 n}, n \geq 2: v_{0} v_{1} \cdots, v_{2 n-1} v_{0}$. Graf gir $G_{2 n}$ diperoleh dengan cara menambahkan satu titik baru, notasikan $c$, yang bertetangga dengan $n$ buah titik di graf $C_{2 n}, n \geq 2$, yaitu titik-titik $v_{0}, v_{2}, \cdots, v_{2 n-2}$. Misalkan dimensi partisi graf Gir $p d\left(G_{2 n}\right)=k$. Pada tulisan ini akan dikaji kembali bahwa banyaknya titik di graf gir $G_{2 n}$ dibatasi oleh dimensi partisinya, yaitu $2 n+1<3 k^{4}(k+2) 2^{k-7}$.
\end{abstract}

Kata Kunci: Partisi penyelesaian, dimensi partisi, graf gir.

\section{Pendahuluan}

Misalkan terdapat suatu graf terhubung $G$. Ambil sebarang titik $v$ di $V$. Jarak $d(u, v)$ antara titik $u$ dan $v$ pada graf $G$ adalah panjang lintasan terpendek dari titik-titik tersebut. Sedangkan jarak terpanjang antara titik-titik pada $V(G)$ didefinisikan sebagai diameter dari graf $G$, ditulis $\operatorname{diam}(G)$. Misal terdapat titik $v \in$ $V(G)$ dan $S$ adalah himpunan bagian dari $V(G)$. Jarak antara $v$ dan $S$ adalah $d(v, S)=\min \{d(v, x) \mid x \in S\}$.

Misalkan $V(G)$ dipartisi menjadi $k$ buah himpunan, $S_{1}, S_{2}, \cdots, S_{k}$ yang sa-ling lepas. Definisikan $\pi=\left\{S_{1}, S_{2}, \cdots, S_{k}\right\}$ sebagai himpunan yang berisikan $k$-partisi tersebut. Misal terdapat titik $v \in V(G)$, maka representasi dari $v$ terhadap $\pi$ didefinisikan sebagai $r(v \mid \pi)=\left(d\left(v, S_{1}\right), d\left(v, S_{2}\right), \cdots, d\left(v, S_{k}\right)\right)$. Jika titik-titik yang berbeda di $G$ mempunyai representasi yang berbeda terhadap $\pi$, maka $\pi$ disebut partisi penyelesaian (resolving partition) graf $G$. Kardinalitas dari partisi penyelesaian minimum disebut dimensi partisi dari $G$, ditulis $p d(G)$.

Graf siklus adalah graf sederhana yang setiap titiknya berderajat dua. Graf siklus dengan $n$ titik dilambangkan dengan $C_{n}$. Graf roda merupakan graf yang diperoleh dengan cara menambahkan satu titik di luar graf siklus $C_{n}$, dan menghubungkan titik baru tersebut dengan semua titik pada $C_{n}$. Graf roda dengan $n+1$ titik dinotasikan dengan $W_{n}$. 
Makalah ini merupakan tinjauan ulang dari rujukan pustaka [3]. Pada makalah ini penulis mengkaji kembali tentang dimensi partisi dari salah satu graf yang mirip dengan graf roda, yaitu graf $\operatorname{Gir} G_{2 n}, n \geq 2$.

\section{Dimensi Partisi dari Graf Gir}

Misalkan diberikan graf siklus genap $C_{2 n}, n \geq 2$ dengan $V\left(C_{2 n}\right)=$ $\left\{v_{0}, v_{1}, \cdots, v_{2 n-1}\right\}$ dan $E\left(C_{2 n}\right)=\left\{v_{i} v_{i+1} \mid i=0,1, \cdots, 2 n-2\right\} \cup\left\{v_{2 n-1} v_{0}\right\}$. Untuk mengkonstruksi graf gir $G_{2 n}$, tambahkan satu titik baru, notasikan dengan $c$, yang bertetangga dengan $n$ titik di $C_{2 n}$, dengan ketentuan, untuk $i=0$ atau 1, tambahkan sisi-sisi $c v_{i}, c v_{i+2}, c v_{i+4}, \cdots, c v_{i+(2 n-2)}$. Jadi $V\left(G_{2 n}\right)=\left\{v_{i} \mid i=\right.$ $0,1, \cdots, 2 n-1\} \cup\{c\}$ dan $E\left(G_{2 n}\right)=\left\{c v_{j} \mid j=0,2, \cdots, 2 n-2\right\} \cup E\left(C_{2 n}\right)$. Dapat dilihat bahwa banyaknya titik graf gir $G_{2 n}$ adalah $2 n+1$, sementara banyaknya sisi graf gir $G_{2 n}$ adalah $3 n$. Pada Gambar 1 berikut diberikan gambar $C_{2 n}$ dan $G_{2 n}$ sebagaimana yang telah didefinisikan di atas.
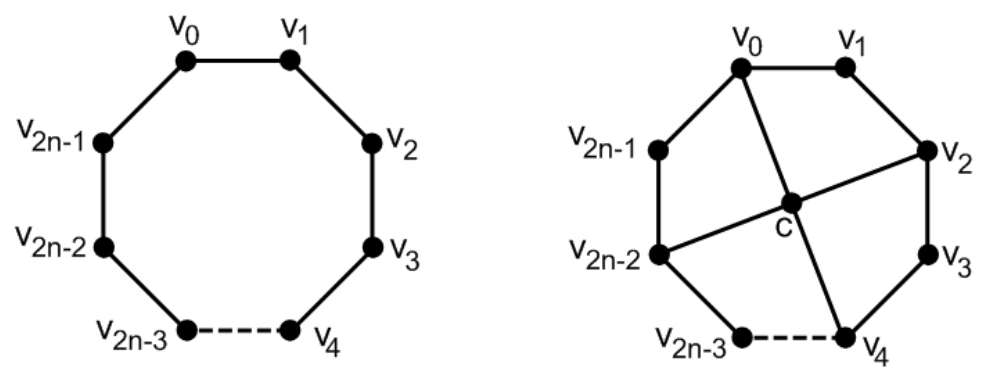

Gambar 1. Graf siklus genap $C_{2 n}$ dan graf gir $G_{2 n}$

Definisi 2.1 dan Definisi 2.2 berikut memberikan pengertian dari jarak antara dua titik dan jarak antara suatu titik terhadap suatu himpunan pada suatu graf.

Definisi 2.1. [3] Misalkan $G=(V, E)$ adalah graf terhubung dan misalkan $S \subseteq V$. Misalkan terdapat suatu titik $v \in V$. Maka jarak titik $v$ terhadap $S$ didefinisikan sebagai $d(v, S)=\min \{d(v, x) \mid x \in S\}$.

Definisi 2.2. [3] Misalkan $G=(V, E)$ adalah graf terhubung dan $u, v \in V$ adalah dua titik sebarang di $G$. Diameter $G$ didefinisikan sebagai jarak maksimum antara setiap dua titik di $G$, dinotasikan $\operatorname{diam}(G)=\max \{d(u, v) \mid u, v \in V(G)\}$.

Selanjutnya pengertian dimensi partisi suatu graf diberikan pada Definisi 2.3 berikut.

Definisi 2.3. [3] Misalkan $G$ adalah suatu graf terhubung dengan himpunan titik $V(G)$ dipartisi menjadi beberapa partisi, sebut $S_{1}, S_{2}, \cdots, S_{k}$. Notasikan $\pi$ sebagai suatu himpunan terurut dari k-partisi, tulis $\pi=\left\{S_{1}, S_{2}, \cdots, S_{k}\right\}$. Misalkan terdapat suatu titik $v$ di $G$, maka representasi $v$ terhadap $\pi$ didefinisikan sebagai jarak dari 
$v$ ke tiap-tiap partisi di $\pi$, ditulis $r(v \mid \pi)=\left(d\left(v, S_{1}\right), d\left(v, S_{2}\right), \cdots, d\left(v, S_{k}\right)\right)$. Untuk selanjutnya $r(v \mid \pi)$ ini disebut vektor penyajian. Jika setiap titik yang berbeda di $G$ mempunyai representasi yang berbeda terhadap $\pi$, maka $\pi$ disebut sebagai partisi penyelesaian. Kardinalitas minimum dari k-partisi penyelesaian terhadap $V(G)$ disebut dimensi partisi dari $G$, dinotasikan dengan $p d(G)$.

Pada Definisi 2.4 berikut diberikan pengertian dari himpunan penyelesaian.

Definisi 2.4. [3] Misalkan $W \subseteq V(G)$ dan $x, y \in V(G)$. Himpunan $W=$ $\left\{w_{1}, w_{2}, \cdots, w_{k}\right\}$ dikatakan himpunan penyelesaian (resolving set) di $G$ jika untuk setiap dua titik $x, y \in V(G)$, dengan $x \neq y$ maka terdapat suatu titik $w_{i} \in W$ sedemikian sehingga $d\left(x, w_{i}\right) \neq d\left(y, w_{i}\right)$.

Contoh 2.5. Misal terdapat graf gir $G_{4}$ dengan $V\left(G_{4}\right)=\left\{c, v_{0}, v_{1}, v_{2}, v_{3}\right\}$. Akan ditunjukkan bahwa $p d\left(G_{4}\right)=3$. Misal $\pi=\left\{S_{1}, S_{2}, S_{3}\right\}$ dengan $S_{1}=\left\{c, v_{0}\right\}, S_{2}=$ $\left\{v_{1}\right\}, S_{3}=\left\{v_{2}, v_{3}\right\}$. Ambil titik $c \in S_{1}$. Maka representasi titik $c$ terhadap $\pi$ adalah $r(c \mid \pi)=\left(d\left(c, S_{1}\right), d\left(c, S_{2}\right), d\left(c, S_{3}\right)\right)=(0,2,1)$. Selanjutnya, ambil titik $v_{0} \in S_{1}$ maka $r\left(v_{0} \mid \pi\right)=(0,1,1)$. Dengan cara yang sama diperoleh :

$$
\begin{aligned}
& r\left(v_{1} \mid \pi\right)=(1,0,1), \\
& r\left(v_{2} \mid \pi\right)=(1,1,0), \\
& r\left(v_{3} \mid \pi\right)=(1,2,0) .
\end{aligned}
$$

Dapat dilihat bahwa karena sebarang titik v di $G_{4}$ mempunyai representasi $r(v \mid \pi)$ yang berbeda, maka haruslah $p d\left(G_{4}\right)=|\pi|=3$.

\section{Batas Atas untuk Orde $G_{2 n}$}

Untuk membuktikan kembali hasil utama pada kajian ini, penulis menggunakan Klaim 3.1 - Klaim 3.4 dan Lema 3.5 - Lema 3.9 sebagai berikut.

Klaim 3.1. Terdapat paling banyak dua angka 1 pada vektor penyajian dari titik tepi selain posisi pertama.

Klaim 3.2. Terdapat paling banyak dua angka 2 pada vektor penyajian dari titik tepi minor selain posisi pertama.

Klaim 3.3. Bilangan terbesar pada vektor penyajian titik minor adalah 4.

Klaim 3.4. Bilangan terbesar pada vektor penyajian titik mayor adalah 3.

Misalkan $p d\left(G_{2 n}\right)=k$. Pada Lema 3.5 - Lema 3.9 berikut ditunjukkan keterkaitan antara $n$ dan $k$ tersebut.

Lema 3.5. Banyaknya representasi yang berbeda dari titik pusat c pada graf gir terhadap partisi dari $V\left(G_{2 n}\right)$ adalah $2^{k-1}$.

Bukti. Misal $p d\left(G_{2 n}\right)=k$ dan $\pi=\left\{S_{1}, S_{2}, \cdots, S_{k}\right\}$ adalah suatu k-partisi terurut dari titik-titik pada $G$. Asumsikan bahwa titik pusat $c \in S_{1}$. Dapat dituliskan 
$r(c \mid \pi)=\left(d\left(c, S_{1}\right), d\left(c, S_{2}\right), \cdots, d\left(c, S_{k}\right)\right)$, yang berisikan $k$ buah unsur. Unsur pertama yaitu $d\left(c, S_{1}\right)$, haruslah 0 . Untuk $k-1$ posisi lainnya, dapat diisi dengan angka 1 atau 2 . Oleh karena itu banyaknya representasi yang berbeda untuk $c$ adalah $2^{k-}$ 七

Lema 3.6. Banyaknya representasi yang berbeda pada titik-titik tepi mayor dalam $S_{1}$ yang mengandung titik pusat c terhadap partisi dari $V\left(G_{2 n}\right)$ adalah $\sum_{i=0}^{2}\left(\begin{array}{c}k-1 \\ i\end{array}\right) 2^{k-i-1}$.

Bukti. Misalkan $v$ merupakan titik mayor pada $S_{1}$, maka posisi pertama pada vektor penyajian $v$ terhadap $\pi$ adalah 0 . Sehingga $k-1$ posisi lainnya dapat diisi dengan angka 1, 2 atau 3. Dari tiga kasus di atas maka banyaknya representasi yang berbeda adalah $\sum_{i=0}^{2}\left(\begin{array}{c}k-1 \\ i\end{array}\right) 2^{k-i-1}$ dimana $i$ adalah banyaknya angka 1 dalam vektor penyajian.

Lema 3.7. Banyaknya representasi yang berbeda pada titik-titik tepi minor dalam $S_{1}$ yang mengandung titik pusat c pada graf gir terhadap partisi dari $V\left(G_{2 n}\right)$ adalah $\sum_{j=0}^{2} \sum_{i=0}^{2}\left(\begin{array}{c}k-1 \\ j\end{array}\right)\left(\begin{array}{c}k-j-1 \\ i\end{array}\right) 2^{k-i-j-1}$.

Bukti. Misal $u$ adalah titik minor di $S_{1}$. Karena posisi pertama pada vektor penyajian titik $u$ terhadap $\pi$ diisi 0 , maka $k-1$ posisi lainnya dapat diisi dengan $1,2,3$, atau 4. Karena paling banyak dua posisi diisi angka 1 (berdasarkan Klaim 1) dan berdasarkan Klaim 2, terdapat paling banyak dua buah angka 2 maka banyaknya representasi yang berbeda adalah $\sum_{j=0}^{2} \sum_{i=0}^{2}\left(\begin{array}{c}k-1 \\ j\end{array}\right)\left(\begin{array}{c}k-j-1 \\ i\end{array}\right) 2^{k-i-j-1}$.

Lema 3.8. Banyaknya representasi yang berbeda pada titik-titik tepi mayor dalam kelas lain selain $S_{1}$ yang mengandung titik pusat c pada graf gir terhadap partisi dari $V\left(G_{2 n}\right)$ adalah $\sum_{i=0}^{2}\left(\begin{array}{c}k-2 \\ i\end{array}\right) 2^{k-i-2}$.

Bukti. Misalkan $w$ adalah titik mayor pada kelas lain selain $S_{1}$. Tanpa mengurangi perumuman dapat diasumsikan bahwa $w \in S_{2}$, maka posisi pertama pada vektor penyajian $w$ terhadap $\pi$ adalah 1 dan posisi kedua diisi oleh 0 . Sehingga $k-2$ posisi lainnya dapat diisi dengan 1, 2 atau 3. Karena terdapat paling banyak dua buah angka 1 (berdasarkan Klaim 1), maka dengan cara yang sama seperti pada pembuktian Lema 3.1.2 diperoleh bahwa banyaknya representasi yang berbeda adalah $\sum_{i=0}^{2}\left(\begin{array}{c}k-2 \\ i\end{array}\right) 2^{k-i-2}$, dimana $i$ adalah banyaknya angka 1 dalam vektor penyajian.

Lema 3.9. Banyaknya representasi yang berbeda pada titik-titik tepi minor dalam kelas lain selain $S_{1}$ yang mengandung titik pusat c pada graf gir terhadap partisi dari $V\left(G_{2 n}\right)$ adalah $2 \sum_{j=0}^{2} \sum_{i=0}^{2}\left(\begin{array}{c}k-2 \\ j\end{array}\right)\left(\begin{array}{c}k-j-2 \\ i\end{array}\right) 2^{k-i-j-2}$.

Bukti. Karena posisi pertama pada vektor penyajian dapat diisi oleh 1 atau 2 dan posisi kedua diisi oleh 0 , sehingga $k-2$ posisi lainnya dapat diisi dengan 1, 2, 3, atau 4. Berdasarkan Klaim 1 dan Klaim 2 dan dengan cara yang sama seperti pada pembuktian Lema 3, maka banyaknya representasi yang berbeda adalah $2 \sum_{j=0}^{2} \sum_{i=0}^{2}\left(\begin{array}{c}k-2 \\ j\end{array}\right)\left(\begin{array}{c}k-j-2 \\ i\end{array}\right) 2^{k-i-j-2}$, dengan $j$ adalah banyaknya angka 1 dan $i$ adalah banyaknya angka 2 dalam vektor penyajian. 
Dengan menggunakan Lema 3.5 - Lema 3.9, akan ditunjukkan bahwa banyaknya titik pada graf Gir dibatasi oleh dimensi partisinya, seperti yang ditunjukkan pada Teorema 3.10 berikut.

Teorema 3.10. Misalkan $n \geq 2$ dan $k$ merupakan dimensi partisi dari $G_{2 n}$, maka orde graf gir $G_{2 n}$ dibatasi oleh dimensi partisinya, yaitu $2 n+1<3 k^{4}(k+2) 2^{k-7}$.

Bukti. Misal $\pi=\left\{S_{1}, S_{2}, \cdots, S_{k}\right\}$ dan titik pusat $c$ berada di $S_{1}$. Maka berdasarkan Lema 3.5 - Lema 3.7 diperoleh bahwa banyaknya titik pada $S_{1}$ adalah

$$
\begin{aligned}
\left|S_{1}\right| & \leq 2^{k-1}+\sum_{i=0}^{2}\left(\begin{array}{c}
k-1 \\
i
\end{array}\right) 2^{k-i-1}+\sum_{j=0}^{2} \sum_{i=0}^{2}\left(\begin{array}{c}
k-1 \\
j
\end{array}\right)\left(\begin{array}{c}
k-j-1 \\
i
\end{array}\right) 2^{k-i-j-1} \\
& =2^{k-7}\left(k^{4}-2 k^{3}+27 k^{2}+14 k+152\right) \\
& <3 k^{4} 2^{k-6}
\end{aligned}
$$

untuk setiap $k \geq 3$.

Berdasarkan Lema 3.8 dan Lema 3.9 maka banyaknya titik pada partisi lainnya adalah

$$
\begin{aligned}
\left|S_{l}\right| & \leq \sum_{i=0}^{2}\left(\begin{array}{c}
k-2 \\
i
\end{array}\right) 2^{k-i-2}+2 \sum_{j=0}^{2} \sum_{i=0}^{2}\left(\begin{array}{c}
k-2 \\
j
\end{array}\right)\left(\begin{array}{c}
k-j-2 \\
i
\end{array}\right) 2^{k-i-j-2}, \\
& =2^{k-7}\left(k^{4}-6 k^{3}+35 k^{2}+46 k+80\right), \\
& <3 k^{4} 2^{k-7}
\end{aligned}
$$

untuk setiap $k \geq 3$.

Karena banyaknya titik di $G_{2 n}$ adalah jumlah titik dari masing-masing kelas partisi, maka diperoleh

$$
\begin{aligned}
2 n+1 & =\sum_{l=1}^{k}\left|S_{l}\right|, \\
& <3 k^{4} 2^{k-6}+3(k-1) k^{4} 2^{k-7} \\
& <3 k^{4}(k+2) 2^{k-7} .
\end{aligned}
$$

Dapat disimpulkan bahwa orde $G_{2 n}$ dibatasi oleh dimensi partisinya.

Contoh 3.11. Diberikan suatu graf gir $G_{6}$, dengan $n=3$ dimana $n$ adalah banyaknya titik di $G_{6}$ yang bertetangga pada $C_{6}$. Akan ditunjukkan bahwa $p d\left(G_{6}\right)=$ 3 dan orde $G_{6}$ dibatasi oleh dimensi partisinya. Misal diambil $\pi=\left\{S_{1}, S_{2}, S_{3}\right\}$, dimana $S_{1}=\left\{c, v_{0}, v_{5}\right\}, S_{2}=\left\{v_{1}, v_{2}\right\}, S_{3}=\left\{v_{3}, v_{4}\right\}$ maka diperoleh representasi 
setiap titik pada graf $G_{6}$ relatif terhadap $\pi$ adalah:

$$
\begin{aligned}
r(c \mid \pi) & =(0,1,1), \\
r\left(v_{0} \mid \pi\right) & =(0,1,3), \\
r\left(v_{1} \mid \pi\right) & =(1,0,2), \\
r\left(v_{2} \mid \pi\right) & =(2,0,1), \\
r\left(v_{3} \mid \pi\right) & =(1,1,0), \\
r\left(v_{4} \mid \pi\right) & =(1,2,0), \\
r\left(v_{5} \mid \pi\right) & =(0,2,1) .
\end{aligned}
$$

Karena representasi setiap titik terhadap $\pi$ pada $G_{6}$ berbeda, maka $\pi$ merupakan himpunan partisi penyelesaian dari $G_{6}$. Karena $\pi=\left\{S_{1}, S_{2}, S_{3}\right\}$ dan $|\pi|=3$ maka $\operatorname{pd}\left(G_{6}\right)=3$.

Kemudian akan ditunjukkan bahwa orde graf gir $G_{6}$ dibatasi oleh dimensi partisinya. Diketahui bahwa $n=3$ dimana $n$ adalah banyaknya titik di $G_{6}$ yang bertetangga pada $C_{6}$. Telah diperoleh bahwa $p d\left(G_{6}\right)=k=3$. Maka berdasarkan Teorema 3.10 , berlaku

$$
\begin{aligned}
2 n+1 & <3 k^{4}(k+2) 2^{k-7}, \\
2(3)+1 & <3\left(3^{4}(3+2)\right) 2^{3-7} \\
6+1 & <3(81(5)) 2^{-4} \\
7 & <76 .
\end{aligned}
$$

Dari contoh di atas dapat dilihat bahwa orde graf gir $G_{6}$ terbatas di atas oleh dimensi partisinya.

\section{Kesimpulan}

Misalkan terdapat graf siklus genap $C_{2 n}$ dengan $n \geq 2$. Notasikan $V\left(C_{2 n}\right)=$ $\left\{v_{0}, v_{1}, \cdots, v_{2 n-1}\right\}$ dan $E\left(C_{2 n}\right)=\left\{v_{i} v_{i+1} \mid i=0,1, \cdots, 2 n-2\right\} \cup\left\{v_{2 n-1} v_{0}\right\}$. Graf gir $G_{2 n}$ diperoleh dengan cara menambahkan satu titik, namakan $c$, yang bertetangga dengan $n$ titik di $C_{2 n}$, yaitu $v_{0}, v_{2}, \cdots, v_{2 n-2}$. Jadi $V\left(G_{2 n}\right)=\left\{v_{i} \mid i=\right.$ $0,1, \cdots, 2 n-1\} \cup\{c\}$ dan $E\left(G_{2 n}\right)=\left\{c v_{j} \mid j=0,2, \cdots, 2 n-2\right\} \cup E\left(C_{2 n}\right)$.

Pada tulisan ini telah dikaji kembali bahwa dimensi partisi graf Gir $G_{2 n}$ dibatasi oleh banyaknya titik pada graf Gir tersebut. Misalkan $n \geq 2$, dengan $n$ adalah banyaknya titik pada $G_{2 n}$ yang bertetangga dengan titik-titik di $C_{2 n}$ dan $k$ merupakan dimensi partisi dari $G_{2 n}$, maka $2 n+1<3 k^{4}(k+2) 2^{k-7}$, untuk setiap $k \geq 3$.

\section{Ucapan Terima kasih}

Penulis mengucapkan terima kasih kepada Ibu Lyra Yulianti, Bapak Admi Nazra, Bapak Syafrizal Sy, Bapak Narwen, dan Bapak Zulakmal yang telah memberikan masukan dan saran sehingga makalah ini dapat diselesaikan dengan baik. 


\section{Daftar Pustaka}

[1] Bondy, J. A dan Murty, U. S. R., 1976, Graph Theory with Applications, Macmillan, London

[2] Chartrand, G., Salehi, E., dan Zhang, P., 2000, The partition dimension of a graph, Aequationes Mathematicae 59: 45 - 54

[3] Javaid, I. dan Shokat S., 2008, On the partition dimension of some wheel related graphs, Prime Research in Mathematica 4: 154 - 164 